\title{
Parents' views on factors that help or hinder breast milk supply in neonatal care units: Systematic review
}

Article in Archives of Disease in Childhood - Fetal and Neonatal Edition · July 2013

DOI: 10.1136/archdischild-2013-304029 · Source: PubMed

5 authors, including:

Elisabete Alves

Institute of Public Health, University of Porto

(8) Carina Rodrigues

Institute of Public Health, University of Porto

46 PUBLICATIONS 157 CITATIONS

18 PUBLICATIONS 58 CITATIONS

SEE PROFILE

SEE PROFILE

Henrique Barros

Institute of Public Health, University of Porto

757 PUBLICATIONS $\mathbf{1 1 , 0 5 9}$ CITATIONS

Susana Silva

Institute of Public Health, University of Porto 139 PUBLICATIONS 383 CITATIONS

SEE PROFILE

SEE PROFILE

Some of the authors of this publication are also working on these related projects:

LIFEPATH - Life-course biological pathways underlying social differences in healthy ageing View project

Screening to Improve Health in Very Preterm Infants in Europe (SHIPS) View project 


\title{
Parents' views on factors that help or hinder breast milk supply in neonatal care units: systematic review
}

\author{
Elisabete Alves, ${ }^{1,2}$ Carina Rodrigues, ${ }^{1,2}$ Sílvia Fraga, ${ }^{1,2}$ Henrique Barros, 1,2 \\ Susana Silva ${ }^{1,2}$
}

${ }^{1}$ Department of Clinical Epidemiology, Predictive Medicine and Public Health, University of Porto Medical School, Porto, Portugal ${ }^{2}$ Institute of Public HealthUniversity of Porto, Porto, Portugal

Correspondence to Elisabete Alves, Department of Clinical Epidemiology, Predictive Medicine and Public Health, University of Porto Medical School, Alameda Professor Hernâni Monteiro, Porto 4200-319, Portugal; ealves@med.up.pt

Received 8 March 2013 Accepted 25 June 2013

To cite: Alves Rodrigues C, Fraga S, et al Arch Dis Child Fetal Neonatal Ed Published Online First: [please include Day Month Year] doi:10.1136/archdischild2013-304029

\section{ABSTRACT}

Objective To synthesise what is known about the parents' views on factors that help or hinder breast milk supply during their infants' hospitalisation in neonatal intensive care units (NICU).

Methods A systematic search of PubMed, ISI WoK, PsycINFO and SciELO, targeting studies presenting original empirical data that examined parents' perspectives regarding breast milk supply experiences in NICU, was performed. Based on content analysis, three independent researchers synthesised the findings of seven studies. Categories of facilitators and barriers were identified using quotations stated in the studies: parents' breast milk supply experience; parents-professionals relationships; characteristics of the NICU; and parents' social background and expectations.

Results The studies, five qualitative and two mixed methods, were published between 1994 and 2011. With heterogeneous study designs, fathers' perspectives were analysed in one article. Only one study defined breastfeeding. According to parents' perspectives, successful breast milk supply in NICU depends on coherent and accurate knowledge about its techniques and benefits, reinforcement of mothers' motivation and alignment between NICU's routines and parents' needs. Parents perceived issues related to their own current breast milk supply experience, simultaneously, as main facilitators and barriers. Parents-professionals relationship constituted the second group of facilitators, but the fourth of barriers. The characteristics of the NICU were more relevant as a barrier than as a facilitator.

Conclusions Although parents' perspectives are grounded on individual child-focused experiences, their emphasis on learning and motivation guided by shortterm goals opens room to the collective intervention of experts. This may facilitate the engagement of mothers, fathers and health professionals on family-centred care.

\section{INTRODUCTION}

The prevalence and duration of breast milk supply among infants admitted to neonatal intensive care units (NICU) tend to be lower than that of fullterm infants, ${ }^{1}{ }^{2}$ despite the documented benefits of maternal milk for babies and mothers. ${ }^{3}$ Breast milk has been associated with several protective effects regarding multiple medical problems related to prematurity. ${ }^{4}$ In fact, feeding human milk to preterm infants may impact their long-term health and development. ${ }^{5-7}$ Additionally, the contribution of breast milk for an early and enhanced infantmother attachment has been previously described. ${ }^{8}$ For mothers of infants hospitalised and in an incubator, breast milk may provide a major and unique

\section{What is already known on this topic}

- Parents are key actors for successful breast milk supply in neonatal intensive care units (NICU).

- Very few studies have focused on the psychosocial needs and opinions of parents which have repercussions on infants' health and well-being.

\section{What this study adds}

- According to parents' perspectives, successful breast milk supply depends on knowledge, reinforcement of mothers' motivation and alignment between NICU's routines and parents' needs.

- The results highlight the need to invest in qualitative and quantitative research regarding parents' views on breast milk supply during hospitalisation in NICU.

- This approach may improve knowledge and optimise the engagement of mothers, fathers and health professionals on family-centred care in NICU.

opportunity to hold and physically connect with their infants. ${ }^{9}$

The perinatal clinical situation has been described as an important predictor of the success of breast milk supply, ${ }^{10}$ with the admission to NICU being one of the strongest predictors of not being exclusively breastfed at discharge. ${ }^{11}$ The vulnerability of preterm infants and the unique challenges posed by the NICU setting, with the separation of the baby from the mother, difficulties in establishing and maintaining a milk supply and having to deal with health professionals in that sociotechnical environment ${ }^{2} 12$ contributed to understand lower rates of breast milk supply among children hospitalised in NICU. In Europe, breastfeeding rates at discharge for very preterm infants varied from 19\% in Burgundy (France) to $70 \%$ in Lazio (Italy), and were higher in countries with high overall breastfeeding rates. ${ }^{1}$

While parents are key actors for successful breast milk supply in NICU, literature highlights the involvement of health professionals, and the availability of adequate equipment and facilities. ${ }^{13}$ Very few studies have focused on the psychosocial needs 
and opinions of parents, ${ }^{14} 15$ which have repercussions on infants' health and well-being. In the last decade, other systematic reviews have synthetised mothers' and fathers' experiences and perceptions of breastfeeding support ${ }^{16}$ and the barriers to breastfeeding in preterm infants, ${ }^{2}$ but they did not access these issues exclusively during the NICU hospitalisation, a setting with specificities that can impact breast milk supply.

Furthermore, listening the parents' voice is a core need for a quality family-centred care, ${ }^{17}$ defined as provision of care that is respectful of and responsive to individual parent's preferences, needs and values. ${ }^{18}$ Therefore, we aimed to analyse and summarise what is known about the parents' views on factors that help or hinder breast milk supply during their infants' hospitalisation in NICU.

\section{METHODS}

The electronic databases, PubMed, ISI Web of Knowledge, PsycINFO and SciELO, were searched to identify all the studies presenting original empirical data on parents' views about facilitators and barriers to breast milk supply during the hospitalisation of babies in NICU. The search covered the full range of publication dates from inception until December 2012, with the expression: "Parents" AND ("perspective"* OR "experience*" OR "Knowledge" OR "Decision Making") AND "Intensive Care Units, Neonatal" AND "Breast Feeding". In PubMed and SciELO, search terms were included as Medical Subject Heading (MeSH) terms. Twelve publications were identified.

The flowchart showing the systematic review process is presented in figure 1. First, studies were excluded based on title and abstract assessment. Three reviewers independently evaluated the studies, following a priori defined criteria for inclusion: written in English, French, Spanish or Portuguese; original studies that evaluate the experiences, knowledge and decisionmaking regarding breast milk supply during hospitalisation in NICU. Whenever the abstract of a particular article was not available, full text was considered for evaluation. ${ }^{19}$ The full texts of the selected articles were then evaluated to decide on their eligibility and availability of relevant data, and five papers were excluded. ${ }^{19-23}$ The main reasons for their exclusion are presented in table 1 . The bibliographic references of the six publications eligible for inclusion were screened to identify potential articles, one additional paper was included. ${ }^{24}$ The three independent reviewers also extracted and synthesised the following data from publications included in this systematic review. First, aiming to characterise the studies, data regarding the year and country of data collection, type of study/methods for data collection, timing of data collection, setting, number of participants, eligibility criteria and breastfeeding definition were collected. Additionally, the first author matched all the keywords mentioned in the studies with $\mathrm{MeSH}$ terms and the respective $\mathrm{MeSH}$ categories, ${ }^{25}$ in order to understand the main medical subheadings addressed in the papers. Second, based on content analysis, ${ }^{26}$ categories of facilitators and barriers to breast milk supply in NICU were identified through quotations stated in the studies. These were then summarised in four main categories of facilitators/barriers, according to the protocol for a thematic analysis $^{27}$ : parents' breast milk supply experience; parents-professionals relationships; characteristics of the NICU; and parents' social background and expectations. The frequency of each theme and category was recorded. Disagreements in abstractions were discussed and resolved by consensus. An almost perfect strengthen of agreement was achieved. ${ }^{26}$

\section{RESULTS}

\section{Study characteristics}

The main characteristics of the seven included studies in this systematic review ${ }^{24-33}$ are presented in table 2 . The studies were published between 1994 and 2011, and five were qualitative and two were mixed methods. The most common method for collecting data was the semistructured interview. Studies were conducted in Sweden $(n=2)$, USA $(n=2)$ and England $(n=1)$, and two publications did not provide this information.

The period of data collection ranged from 6 months to 2 years and 5 months, in the three studies that reported it. The timing of data collection was highly variable across the studies, ranging from 1 to 2 weeks after admission to the NICU until 3 months after infant's discharge from hospital. Three out of the seven studies did not report when data collection took place. The setting also varied between the studies, with only two studies including several neonatal units. ${ }^{28} 31$

The number of participants ranged from 9 to 178 mothers, and only one study also examined the fathers' perspectives on facilitators and barriers to breast milk supply in NICU. ${ }^{30}$ The eligibility criteria of the participants were heterogeneous but, in general, single mothers, those who were not able to speak the native language and those whose babies had congenital malformations or were very close to death were excluded. The socioeconomic characterisation of the participants was very succinct or absent, ${ }^{24}$ which in articulation with the different settings, timing of data collection, eligibility criteria and sample sizes makes it impossible to compare the studies directly. Furthermore, only one article defined breastfeeding, considering it as 'skin-to-skin contact that occurs when an infant's face touches the mother's breast with the intention of having the infant suckle the nipple to obtain human milk'. ${ }^{32}$

The MeSH categories of the keywords included in the studies are presented in table 3 . The keywords were mainly concentrated in 4 out of $19 \mathrm{MeSH}$ categories: Persons $(n=4)$, Psychiatry and Psychology $(n=4)$, Phenomena and Processes $(n=4)$, and Health Care $(n=3)$. Only the MeSH terms "Breast Feeding", "Lactation" and "Intensive Care Units, Neonatal" were included in more than one article. Two papers did not present keywords, ${ }^{28} 32$ and one-third of keywords did not have a MeSH term attributable.

\section{Facilitators and barriers to breast milk supply in NICU}

Parents perceived issues related to their own current breastfeeding experience as mothers and fathers as the main facilitators and the main barriers to breastfeeding in NICU (table 4). In particular, its facilitators were the contribution to infant's growth and well-being, the sense of 'normality', the opportunity to hold and connect with the infant and the learning of techniques to breastfeed, as well as the knowledge about infant's and women's bodies and behaviours. On the contrary, difficulties with pumping and worries surrounding inadequate milk supply emerged as the main barriers.

The relation between parents and health professionals constituted the second group of facilitators, but the last group of barriers. Although the staff perceptions of the parents' and infants' needs may differ from those of parents, mothers and fathers highlighted the importance of positive, consistent and continuous reinforcement and feedback to stimulate mother's motivation and the provision of accurate information regarding breast milk supply strategies and techniques.

The characteristics of the NICU proved a higher relevance as a barrier than as a facilitator. The stressful nature of the NICU, 


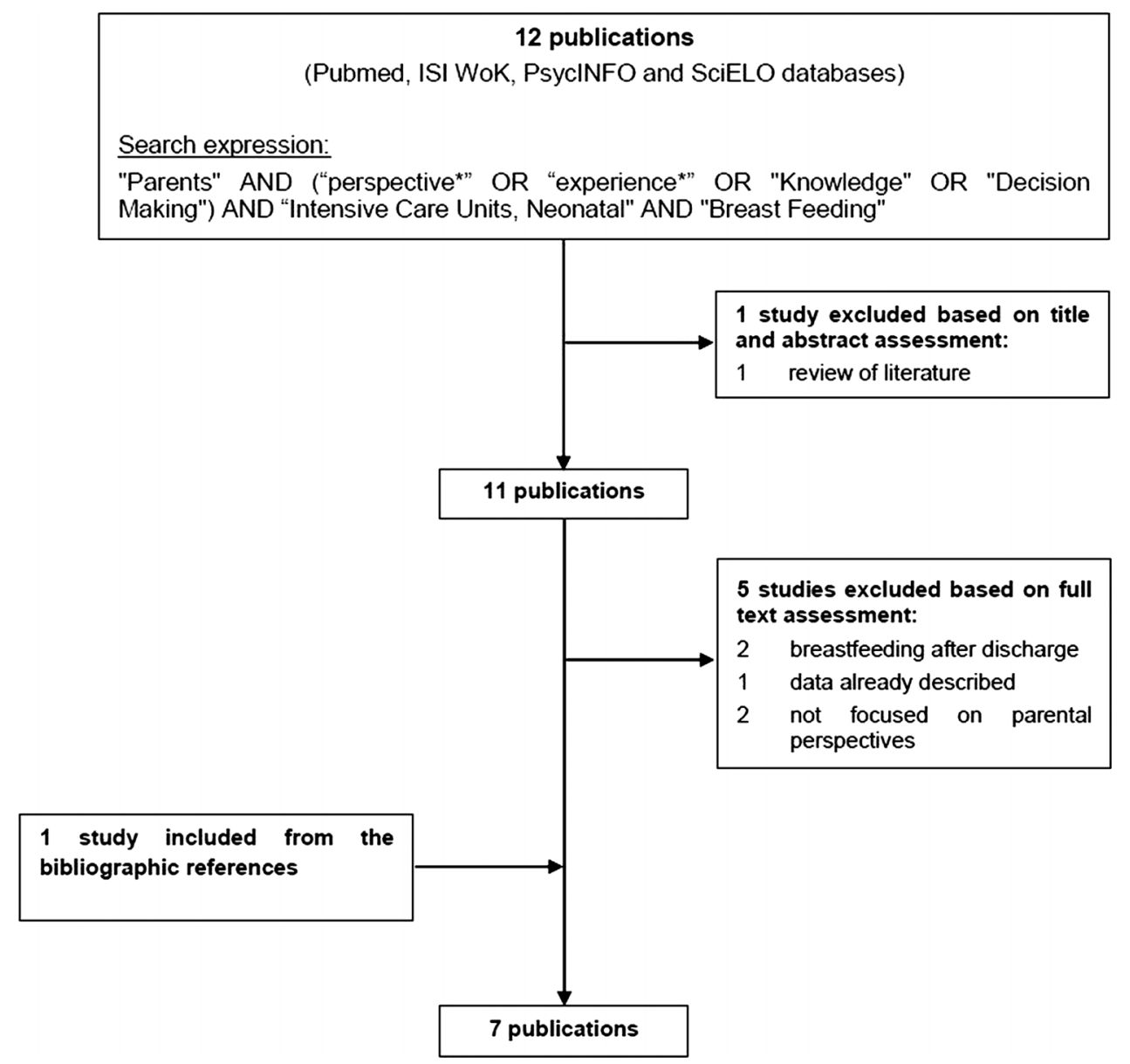

Figure 1 Systematic review flowchart.

the physical separation from infants, the lack of privacy and the structured feeding routine provided a large contribution to the barriers, while the availability of peer counsellors and sterile supplies, as well as the perception of the NICU environment as comfortable facilitated breast milk supply.

Parents' social background and expectations were perceived as neither main contributors nor barriers to a successful breast milk supply experience in the NICU. While it reveals the lowest relevance as contributors, lack of role models and/or social support, isolation and competing time demands were highlighted as barriers.

\section{DISCUSSION}

This study assessed the published evidence on parents' perspectives regarding the facilitators and barriers to breast milk supply

\begin{tabular}{|c|c|}
\hline $\begin{array}{l}\text { First author, year of } \\
\text { publication }\end{array}$ & Exclusion criteria \\
\hline de Souza, $2010^{20}$ & $\begin{array}{l}\text { The data described in the paper focused the } \\
\text { experiences of breastfeeding after discharge }\end{array}$ \\
\hline Dweck, $2008^{21}$ & The study was not focused on parental perspectives \\
\hline Hallbauer, $2002^{22}$ & The study was not focused on parental perspectives \\
\hline Miracle, $2004^{19}$ & $\begin{array}{l}\text { Data already described in another paper included in } \\
\text { the revision }{ }^{29}\end{array}$ \\
\hline Wataker, $2012^{23}$ & $\begin{array}{l}\text { The data described in the paper focused the } \\
\text { experiences of breastfeeding after discharge }\end{array}$ \\
\hline
\end{tabular}

of children hospitalised in the NICU, according to which a successful experience is linked with three main issues. The first group concerns coherent and accurate knowledge about breast milk supply, namely regarding techniques for expression and storage of breast milk, its benefits and women's and newborn's bodies and behaviours. The second group includes continuous and positive feedback with health professionals to stimulate mothers' motivation. The latter refers to the alignment between the NICU's routines and the parents' needs, while safeguarding the privacy and proximity between mother, father and child. The findings highlight the multifaceted nature of breastfeeding as a gendered embodied experience, ${ }^{34}$ in the sense that it is perceived, simultaneously, as a biological and social phenomena or process (with parents emphasising, as main facilitators of breast milk supply in NICU, knowledge of its nutritional and health benefits and physical and emotional closeness with infants) and a female issue (only one of the studies included in this systematic review considered the perspectives of the father).

For mothers with infants hospitalised in NICU, the opportunity of establishing such physical and symbolic connection may be the only context where they are able to hold or care for their infants and feel involved in their growth and well-being, which will interfere with the development of the bonding between mothers and infants. ${ }^{35}$ In fact, one major dimension of the infants' care concerns the nutritional aspects, due to the importance of giving adequate milk to the child for optimal weight gain and growth, contributing to the improvement of his/her actual and future global health status. ${ }^{36}$ Breastfeeding generates situations that promote the development of women's sense of 
Table 2 Main characteristics of the studies

\begin{tabular}{|c|c|c|c|c|c|c|c|}
\hline $\begin{array}{l}\text { First author, } \\
\text { year of } \\
\text { publication }\end{array}$ & $\begin{array}{l}\text { Period of data } \\
\text { collection }\end{array}$ & Country & $\begin{array}{l}\text { Type of study/methods } \\
\text { for data collection }\end{array}$ & $\begin{array}{l}\text { Timing of data } \\
\text { collection }\end{array}$ & Setting & $\begin{array}{l}\text { Number of } \\
\text { participants }\end{array}$ & Eligibility \\
\hline Nyqvist, $1994^{24}$ & $\begin{array}{l}\text { September } \\
1989-\text { August } \\
1990\end{array}$ & Sweden & $\begin{array}{l}\text { Qualitative and } \\
\text { quantitative } \\
\text { Descriptive } \\
\text { Infants' medical } \\
\text { records and telephone } \\
\text { interviews }\end{array}$ & $\begin{array}{l}3 \text { months after } \\
\text { discharge from the } \\
\text { unit }\end{array}$ & $\begin{array}{l}\text { NICU of the University Hospital, } \\
\text { Uppsala }\end{array}$ & 178 mothers & $\begin{array}{l}\text { Swedish-speaking } \\
\text { Whose infants were full-term singletons (37-42 gestational weeks), } \\
\text { had no congenital malformations and were not treated with intensive } \\
\text { care techniques (such as oxygen, continuous positive airway pressure, } \\
\text { assisted ventilation and/or total parenteral nutrition) } \\
\text { Whose infants were admitted to the NICU within the first day of life } \\
\text { and discharged from the NICU within } 6 \text { days }\end{array}$ \\
\hline Jaeger, $1997^{28}$ & NR & England & $\begin{array}{l}\text { Qualitative and } \\
\text { quantitative } \\
\text { Cross-sectional } \\
\text { - Semistructured } \\
\text { questionnaire }\end{array}$ & NR & $\begin{array}{l}\text { Neonatal care units of } 3 \text { London } \\
\text { hospitals }\end{array}$ & 44 mothers & $\begin{array}{l}\text { English-speaking (except if a translator was available) and who were } \\
\text { themselves well } \\
\text { Whose babies were not very close to death or when the staff did not } \\
\text { consider them inappropriate for inclusion } \\
\text { Whose preterm or sick neonates were admitted to the neonatal care } \\
\text { units for more than } 6 \text { days and less than } 3 \text { months after delivery }\end{array}$ \\
\hline Miracle, $2004^{29}$ & NR & USA & $\begin{array}{l}\text { Qualitative } \\
\text { Descriptive } \\
\text { Demographic } \\
\text { questionnaire and } \\
\text { semistructured } \\
\text { interview }\end{array}$ & $\begin{array}{l}\text { At least } 30 \text { days } \\
\text { postbirth }\end{array}$ & $\begin{array}{l}\text { 52-bed Special Care Nursery, Rush } \\
\text { University Medical Center, tertiary } \\
\text { urban NICU }\end{array}$ & 21 mothers & $\begin{array}{l}\text { Mothers who stated to intent not to breastfeed at the time of birth, } \\
\text { with subsequent initiation of lactation with breast pump and that } \\
\text { continued to use the breast pump at } 30 \text { days postbirth } \\
\text { Whose infants birth weight was } \leq 1500 \mathrm{~g}\end{array}$ \\
\hline Bernaix, $2006^{30}$ & NR & USA & $\begin{array}{l}\text { Qualitative } \\
\text { Descriptive } \\
\text { Semistructured } \\
\text { interviews }\end{array}$ & $\begin{array}{l}\text { Within } 1-2 \text { weeks of } \\
\text { the infant's } \\
\text { admission to the } \\
\text { unit }\end{array}$ & $\begin{array}{l}\text { 52-bed, tertiary-care NICU in a free } \\
\text { standing paediatric hospital that is } \\
\text { part of an academic medical centre }\end{array}$ & $\begin{array}{l}9 \text { mother- } \\
\text { father pairs }\end{array}$ & $\begin{array}{l}\text { Mothers married or cohabitating, with at least } 15 \text { years of age and } \\
\text { that choose to lactate } \\
\text { With a premature infant (between } 24 \text { and } 32 \text { weeks of gestation), } \\
\text { hospitalised in the NICU }\end{array}$ \\
\hline Flacking, $2006^{31}$ & $\begin{array}{l}\text { January 2001- } \\
\text { May } 2003\end{array}$ & Sweden & $\begin{array}{l}\text { Qualitative } \\
\text { Descriptive } \\
\text { In-depth interviews }\end{array}$ & $\begin{array}{l}\text { At least } 4 \text { weeks } \\
\text { after discharge from } \\
\text { the unit }\end{array}$ & $\begin{array}{l}7 \text { NUs spread geographically all over } \\
\text { Sweden, } 3 \text { at university hospitals } \\
\text { and } 4 \text { at country hospitals }\end{array}$ & 25 mothers & $\begin{array}{l}\text { Swedish-speaking, without life-threatening illness or diagnosed mental } \\
\text { illness, who experienced pumping breast milk or breastfeeding during } \\
\text { the time in the NU } \\
\text { Whose infants born before } 32 \text { gestational weeks and had no } \\
\text { congenital malformation preventing breastfeeding or severe illness } \\
\text { (such as a cerebral haemorrhage grade III and IV or a chromosome } \\
\text { aberration) }\end{array}$ \\
\hline Boucher, $2011^{32}$ & NR & Canada & $\begin{array}{l}\text { Qualitative } \\
\text { Descriptive } \\
\text { Face-to-face } \\
\text { semistructured } \\
\text { interviews }\end{array}$ & NR & $\begin{array}{l}\text { Level III NICU in a large urban } \\
\text { hospital }\end{array}$ & 10 mothers & $\begin{array}{l}\text { Mothers able to understand and speak English or French, whose } \\
\text { infants were between } 33 \text { and } 36 \text { weeks gestational age, that have } \\
\text { begun to breastfeed and without a story of substance abuse and/or } \\
\text { undergoing methadone treatment } \\
\text { Whose infants had not been apprehended and not had a diagnosis of } \\
\text { grade III or IV cerebral abnormalities } \\
\text { Whose infants have been in the NICU for at least } 5 \text { days }\end{array}$ \\
\hline Rossman, $2011^{33}$ & $\begin{array}{l}\text { October 2008- } \\
\text { March } 2009\end{array}$ & USA & $\begin{array}{l}\text { Qualitative } \\
\text { Descriptive } \\
\text { - Semistructured } \\
\text { interview }\end{array}$ & NR & $\begin{array}{l}\text { 57-bed tertiary care NICU, } \\
\text { Metropolitan Medical Center }\end{array}$ & 21 mothers & $\begin{array}{l}\text { Mothers able to speak and understand English, with } \geq 18 \text { years of age } \\
\text { and with at least } 3 \text { interactions with a breastfeeding peer counsellor } \\
\text { Whose very low birth weight infant was hospitalised in the NICU and } \\
\text { was expected to survive }\end{array}$ \\
\hline
\end{tabular}


Table 3 Medical Subject Heading (MeSH) categories of the keywords included in the studies

\begin{tabular}{|c|c|c|c|}
\hline MeSH categories & $\mathbf{n}$ & MeSH terms & Keywords \\
\hline Persons & 4 & $\begin{array}{l}\text { Infant, low birth weight } \\
\text { Infant, newborn } \\
\text { Infant, premature } \\
\text { Infant, very low birth weight }\end{array}$ & $\begin{array}{l}\text { Low birth weight infants } \\
\text { Newborn } \\
\text { Premature infant } \\
\text { Very low birth weight infants }\end{array}$ \\
\hline Phenomena and processes & 4 & $\begin{array}{l}\text { Breastfeeding }(n=2) \\
\text { Lactation }(n=2)\end{array}$ & $\begin{array}{l}\text { Breastfeeding }(n=2) \\
\text { Lactation }(n=2)\end{array}$ \\
\hline Psychiatry and psychology & 4 & $\begin{array}{l}\text { Breastfeeding }(n=2) \\
\text { Breast milk expression } \\
\text { Family }\end{array}$ & $\begin{array}{l}\text { Breastfeeding }(n=2) \\
\text { Breast pumping } \\
\text { Family }\end{array}$ \\
\hline Healthcare & 3 & Intensive care units, neonatal $(n=3)$ & Neonatal intensive care units $(n=3)$ \\
\hline Anthropology, education, sociology and social phenomena & 1 & Family & Family \\
\hline Geographical locations & 1 & Sweden & Sweden \\
\hline NA & 7 & No MeSH term & $\begin{array}{l}\text { Breastfeeding decision } \\
\text { Breastfeeding support } \\
\text { Maternal attainment } \\
\text { Mothers' milk } \\
\text { Neonatal unit } \\
\text { Peer counselling } \\
\text { Social bonds }\end{array}$ \\
\hline
\end{tabular}

Two papers did not present keywords. ${ }^{28}$

herself as a good mother ${ }^{37}$ which may contribute for a higher sensitivity during early infancy and secure attachment. ${ }^{8}$ Furthermore, breast milk supply may facilitate the establishment of the bonding between fathers and infants, and men's involvement and support have been consistently associated with breastfeeding initiation and maintenance, enhancing family health. ${ }^{38}$ 39 Therefore, in the context of the NICU, where the development of parental roles appears to be considerably delayed, health professionals must take into account the physical and psychosocial needs of mothers, fathers and infants when offering advice and support to the families in the decision-making process regarding breastfeeding. ${ }^{37} 40$

Our results reveal that parents' perspectives on breast milk supply facilitators and barriers in NICU are grounded on parental personal experiences focused on child hospitalisation. Across the studies, there is almost no reflexivity concerning the influence of parents' socio-economic position and previous expectations around breastfeeding, as well as there are no references to strategies of public health interventions. Although the individual dimension is highlighted in this specific context, parents' emphasis on learning and motivation guided by short-term goals opens room to the collective dimension, where health professionals and expert peers had a vital role in providing coherent information and positive reinforcement, while teaching and training techniques to facilitate rewarding breastfeeding experiences. Furthermore, assisting parents in understanding their infant's signals can allow them to feel more competent in their parental role and, consequently, in their ability to breastfeed. ${ }^{41}$ Thus, breast milk supply optimisation stresses the importance of developing health education tools proclaiming its short-term benefits for mothers, fathers and infants, as well as effective communication adjusted to the socio-economic position of each mother and father, giving them the opportunity to ask questions and to voice concerns. In addition, other factors that help breast milk supply than those perceived by parents of children hospitalised in NICU must be emphasised, such as staff training, ${ }^{13}$ the engagement of health professionals and the availability of adequate equipment and facilities.

To the best of our knowledge, this is the first study to systematically review parents' perspectives regarding the facilitators and barriers to breast milk supply of children hospitalised in the NICU. Their voices are essential to sustain the design of quality family-centred care, ${ }^{17}$ wherein institutional resources and personnel are organised around parents' preferences, needs and values. The adequate incorporation of parents' perspectives into healthcare delivery needs to consider the specificities of the setting. Despite sociocultural specificities regarding breast milk supply and wide differences between NICU, the identification of common facilitators and barriers among countries points the existence of cross-sectional factors that should constitute a privileged target for intervention. A major strength of this study was the use of four search engines supplemented by scanning the reference list of eligible studies, three investigators and two methods of analysis, reassuring triangulation and validation, as well as an almost perfect strength of agreement at intra- and inter-rater reliability. ${ }^{26}$

A considerable heterogeneity was observed across the studies, especially regarding the number of participants, the moment of data collection, the setting and the eligibility criteria. Additionally, the diminutive number of studies included in the review, five qualitative and two mixed methods, performed in very specific settings and, most, with small sample sizes, make impossible the comparison among them. Publications using quantitative methods were not included in our review since those retrieved by the search expression were not focused on parental perspectives regarding breastfeeding in NICU. Furthermore, only one study ${ }^{32}$ presented a definition of breastfeeding, which means that each paper could use different definitions not directly comparable. The WHO defines breastfeeding as breast milk being received by the child directly from the maternal breast, expressed or from a wet nurse, not taking into account the physical contact between mothers and infants when classifying breast milk supply as exclusive, predominant and complementary. ${ }^{42}$ In accordance with this view, most of interventions to promote breast milk supply in NICU have focused on the physiological benefits of breastfeeding. ${ }^{2}$ Even those that value the skin-to-skin contact do it in the sense of improving nourishment, health outcomes and the duration of breast milk supply. ${ }^{13}$ 43 However, as pointed out in this review, parents often valued breastfeeding as an opportunity to hold and 
Table 4 Facilitators and barriers to breast milk supply in neonatal intensive care units (NICU), according to parents' expectations and experiences

\begin{tabular}{|c|c|c|}
\hline & $\begin{array}{l}\text { Facilitators } \\
\text { Frequency (n) }\end{array}$ & $\begin{array}{l}\text { Barriers } \\
\text { Frequency (n) }\end{array}$ \\
\hline Breast milk supply current experience & 38 & 27 \\
\hline Nourishment and contribution to infant's growth and well-being & $6^{28-33}$ & \\
\hline Support sense of 'normality' & $6^{28-33}$ & \\
\hline Opportunity to hold and connect with infants & $5^{24} 29-32$ & \\
\hline To learn about infant's and women's bodies and behaviours & $5^{24} 2931-33$ & \\
\hline To learn about techniques and strategies & $5^{24} 2931-33$ & \\
\hline Accurate/inaccurate knowledge regarding breast milk supply benefits & 428293233 & $2^{29} 30$ \\
\hline Awareness of infant vulnerability & $3^{282932}$ & $4^{2430-32}$ \\
\hline To compensate the baby & $3^{31-33}$ & \\
\hline Use of electric pump versus hand pump & $1^{28}$ & \\
\hline Difficulties with pumping* & & $7^{24} 28-33$ \\
\hline Worries surrounding inadequate milk supply & & $6^{24} 28-303233$ \\
\hline Delays in starting to express and supplying milk & & 424282931 \\
\hline Desire for more rapid weight gain & & $2^{2832}$ \\
\hline Feelings of failure & & $2^{3132}$ \\
\hline Parents-professionals relationships & 14 & 10 \\
\hline Positive reinforcement and feedback (motivation) & $6^{24} 282931-33$ & \\
\hline Provision of accurate information (guidance) & $624282931-33$ & \\
\hline Confidence in healthcare providers & $2^{30} 31$ & \\
\hline Staff perceptions of needs differ from those of parents & & $5^{24} 2830-32$ \\
\hline Inconsistent information/conflicting advice & & $3^{242831}$ \\
\hline Lack of expert advice & & $2^{2428}$ \\
\hline Characteristics of NICU & 11 & 20 \\
\hline Availability of peer counsellors & 428293133 & \\
\hline Availability/unavailability of sterile supplies & $3^{282933}$ & $1^{28}$ \\
\hline Comfortable/stressful NICU environment & $3^{282931}$ & $5^{24} 30-33$ \\
\hline Structured feeding routine & $1^{31}$ & $3^{243132}$ \\
\hline Physical separation from infants & & 424283031 \\
\hline Lack of privacy & & $3^{242831}$ \\
\hline Distance (home/hospital; NICU/maternity units) & & $2^{2430}$ \\
\hline 'Exclusion' of the father & & $1^{31}$ \\
\hline Inability of other family members to visit the infant & & $1^{30}$ \\
\hline Parents' social background and expectations & 7 & 13 \\
\hline Parents' mutual commitment to provide breast milk & $3^{29-31}$ & \\
\hline Existence/lack of social support & $2^{2931}$ & $3^{28-30}$ \\
\hline Hope that supplying breast milk will be easier once home & $1^{32}$ & \\
\hline Take the decision before delivery & $1^{28}$ & \\
\hline Competing time demands & & $3^{24} 2930$ \\
\hline Lack of role models & & $3^{282933}$ \\
\hline Separation from other family members/friends & & $3^{243031}$ \\
\hline Low socio-economic status & & $1^{31}$ \\
\hline
\end{tabular}

*Pain, transport of milk, levels of stimulation, feelings of exhaustion and frustration.

connect with infants. Therefore, the message for breast milk supply promotion should articulate the major benefits regarding the nourishment of the child with the opportunity to establish physical contact.

The lack of keywords in two articles, as well as the non-use of $\mathrm{MeSH}$ terms in more than one-third of the keywords, may preclude the inclusion of relevant studies, as well as the dissemination of their results to a broad public. Therefore, it is important to stress the need of including keywords in the papers published in the field of biomedical and health sciences and, preferably, $\mathrm{MeSH}$ terms, because these are useful tools to standardise the terminology and to clarify concepts and include them into hierarchical categories, ${ }^{25}$ contributing to resolve lexical ambiguities. ${ }^{44}$
In conclusion, further research should clearly state the definition of breastfeeding and be performed in different countries and settings, for allowing integration and comparison of findings to better understand parents' perspectives of breast milk supply in NICU. Our results highlight the need to invest in qualitative and quantitative research regarding parents' views on breast milk supply during hospitalisation in NICU in order to improve knowledge and to facilitate the implementation of family-centred care. This may be useful for adjusting psychosocial and educational interventions, and healthcare to each family, mother and father. Such an approach may optimise the engagement of mothers, fathers and health professionals on family-centred care in NICU. 
Contributors Each author participated sufficiently in the work to take public responsibility for its content, fulfilling the criteria of authorship. EA collaborated in the acquisition, analysis and interpretation of the data and wrote the article. CR collaborated in the acquisition, analysis and interpretation of the data and reviewed the article. SF analysed and interpreted the data, and reviewed the article critically. HB analysed and interpreted the data, and reviewed the article critically. SS designed the study, collaborated in the acquisition, analysis and interpretation of the data and reviewed the article critically for important intellectual content. All authors approved the final version.

Funding This study was co-financed through FEDER funding from the Operational Competitiveness Programme-COMPETE and through national funding from the FCT -Foundation for Science and Technology (Portuguese Ministry of Education and Science) within the project FCOMP-01-0124-FEDER-019902.

\section{Competing interests None.}

Provenance and peer review Not commissioned; externally peer reviewed.

\section{REFERENCES}

1 Bonet $\mathrm{M}$, Blondel $\mathrm{B}$, Agostino R, et al. Variations in breastfeeding rates for very preterm infants between regions and neonatal units in Europe: results from the MOSAIC cohort. Arch Dis Child Fetal Neonatal Ed 2011:96:F450-2.

2 Callen J, Pinelli J. A review of the literature examining the benefits and challenges, incidence and duration, and barriers to breastfeeding in preterm infants. Adv Neonatal Care 2005;5:72-88; quiz 89-92.

3 American Academy of Pediatrics. Breastfeeding and the use of human milk. Pediatrics 2012;129:e827-41.

4 Boo NY, Puah CH, Lye MS. The role of expressed breastmilk and continuous positive airway pressure as predictors of survival in extremely low birthweight infants. J Trop Pediatr 2000:46:15-20.

5 Boyd CA, Quigley MA, Brocklehurst P. Donor breast milk versus infant formula for preterm infants: systematic review and meta-analysis. Arch Dis Child Fetal Neonatal Ed 2007:92:F169-75.

6 Beaino G, Khoshnood B, Kaminski M, et al. Predictors of the risk of cognitive deficiency in very preterm infants: the EPIPAGE prospective cohort. Acta Paediatr 2011:100:370-8.

7 Schanler RJ. Outcomes of human milk-fed premature infants. Semin Perinatol 2011:35:29-33.

8 Britton JR, Britton HL, Gronwaldt V. Breastfeeding, sensitivity, and attachment. Pediatrics 2006;118:e1436-43.

9 Sweet L. Expressed breast milk as 'connection' and its influence on the construction of 'motherhood' for mothers of preterm infants: a qualitative study. Int Breastfeed J 2008:3:30-42

10 Espy KA, Senn TE. Incidence and correlates of breast milk feeding in hospitalized preterm infants. Soc Sci Med 2003:57:1421-8.

11 Scott JA, Binns CW, Graham KI, et al. Temporal changes in the determinants of breastfeeding initiation. Birth 2006:33:37-45.

12 Singer LT, Salvator A, Guo S, et al. Maternal psychological distress and parenting stress after the birth of a very low-birth-weight infant. JAMA 1999;281:799-805.

13 Renfrew MJ, Dyson L, McCormick F, et al. Breastfeeding promotion for infants in neonatal units: a systematic review. Child Care Health Dev 2010;36:165-78.

14 Ward K. Perceived needs of parents of critically ill infants in a neonatal intensive care unit (NICU). Pediatr Nurs 2001;27:281-6

15 Saenz P, Cerda M, Diaz JL, et al. Psychological stress of parents of preterm infants enrolled in an early discharge programme from the neonatal intensive care unit: a prospective randomised trial. Arch Dis Child Fetal Neonatal Ed 2009:94:F98-104.

16 McInnes RJ, Chambers JA. Supporting breastfeeding mothers: qualitative synthesis. J Adv Nurs 2008:62:407-27.

17 Malusky SK. A concept analysis of family-centered care in the NICU. Neonatal Netw 2005:24:25-32.

18 Corrigan J, Donaldson M, Kohn L, et al. Crossing the quality Chasm: a new health system for the 21st century. Washington, DC: Institute of Medicine, National Academy of Sciences, National Academy Press, 2001.

19 Miracle DJ, Meier PP, Bennett PA. Making my baby healthy: changing the decision from formula to human milk feedings for very-low-birth-weight infants. Adv Exp Med Biol 2004;554:317-19.
20 de Souza NL, Pinheiro-Fernandes AC, Clara-Costa Ido C, et al. Domestic maternal experience with preterm newborn children. Rev Salud Publica (Bogota) 2011;12:356-67.

21 Dweck N, Augustine M, Pandya D, et al. NICU lactation consultant increases percentage of outborn versus inborn babies receiving human milk. J Perinatol 2008;28:136-40

22 Hallbauer U, Grobler JM, Niemand I. Factors influencing a mother's choice of feeding after discharge of her baby from a neonatal unit. S Afr Med J 2002:92:634-7.

23 Wataker H, Meberg A, Nestaas E. Neonatal family care for 24 hours per day: effects on maternal confidence and breast-feeding. I Perinat Neonatal Nurs 2012:26:336-42.

24 Nyqvist KH, Sjoden PO, Ewald U. Mothers' advice about facilitating breastfeeding in a neonatal intensive care unit. J Hum Lact 1994:10:237-43.

25 Pubmed. MeSH Tree Structures. 2012. http://www.nlm.nih.gov/mesh/2012/mesh_ browser/MeSHtree.html. Retrieved 16 Ocober 2012.

26 Stemler S. An overview of content analysis. Pract Asses Res Eval 2001;7:1-9.

27 Mays N, Pope C, Popay J. Systematically reviewing qualitative and quantitative evidence to inform management and policy-making in the health field. $J$ Health Serv Res Policy 2005;10(Suppl 1):6-20.

28 Jaeger MC, Lawson M, Filteau S. The impact of prematurity and neonatal illness on the decision to breast-feed. J Adv Nurs 1997;25:729-37.

29 Miracle DJ, Meier PP, Bennett PA. Mothers' decisions to change from formula to mothers' milk for very-low-birth-weight infants. J Obstet Gynecol Neonatal Nurs 2004:33:692-703

30 Bernaix LW, Schmidt CA, Jamerson PA, et al. The NICU experience of lactation and its relationship to family management style. MCN Am J Matern Child Nurs 2006;31:95-100.

31 Flacking R, Ewald U, Nyqvist KH, et al. Trustful bonds: a key to 'becoming a mother' and to reciprocal breastfeeding. Stories of mothers of very preterm infants at a neonatal unit. Soc Sci Med 2006;62:70-80.

32 Boucher CA, Brazal PM, Graham-Certosini C, et al. Mothers' breastfeeding experiences in the NICU. Neonatal Netw 2011;30:21-8.

33 Rossman B, Engstrom JL, Meier PP, et al. 'They've walked in my shoes': mothers of very low birth weight infants and their experiences with breastfeeding peer counselors in the neonatal intensive care unit. I Hum Lact 2010:27:14-24.

34 Krieger N. Embodiment: a conceptual glossary for epidemiology. J Epidemiol Community Health 2005;59:350-5.

35 Aagaard H, Hall EO. Mothers' experiences of having a preterm infant in the neonatal care unit: a meta-synthesis. J Pediatr Nurs 2008;23:e26-36.

36 Roze JC, Darmaun D, Boquien CY, et al. The apparent breastfeeding paradox in very preterm infants: relationship between breast feeding, early weight gain and neurodevelopment based on results from two cohorts, EPIPAGE and LIFT. BMJ Open 2012;2:e000834.

37 Fenwick J, Barclay L, Schmied V. Craving closeness: a grounded theory analysis of women's experiences of mothering in the Special Care Nursery. Women Birth 2008:21:71-85.

38 Arora S, McJunkin C, Wehrer J, et al. Major factors influencing breastfeeding rates: mother's perception of father's attitude and milk supply. Pediatrics 2000;106:E67.

39 Meedya S, Fahy K, Kable A. Factors that positively influence breastfeeding duration to 6 months: a literature review. Women Birth 2010;23:135-45.

40 Flacking $\mathrm{R}$, Lehtonen $\mathrm{L}$, Thomson $\mathrm{G}$, et al. Closeness and separation in neonatal intensive care. Acta Paediatr 2012;101:1032-7.

41 McCarter-Spaulding DE, Kearney MH. Parenting self-efficacy and perception of insufficient breast milk. J Obstet Gynecol Neonatal Nurs 2001; 30:515-22.

42 World Health Organization (WHO). Indicators for assessing infant and young child feeding practices: conclusions of a consensus meeting held 6-8 November 2007 in Washington D.C., USA. Parte 1-definitions. France: WHO Press, 2008.

43 Flacking $\mathrm{R}$, Ewald $\mathrm{U}$, Wallin L. Positive effect of kangaroo mother care on long-term breastfeeding in very preterm infants. J Obstet Gynecol Neonatal Nurs 2011:40:190-7.

44 Stevenson M, Guo Y, Gaizauskas R, et al. Disambiguation of biomedical text using diverse sources of information. BMC Bioinformatics 2008;9(Suppl 11):S7. 